\title{
Tragedia, comedia y diálogo socrático: el Banquete entre los géneros teatrales, Sócrates entre la belleza y la fealdad, Ẽ $\omega$ ç entre lo elevado y lo bajo
}

\author{
Andrés Federico Racket \\ Universidad de Buenos Aires \\ andres.racket@gmail.com
}

\begin{abstract}
Tragedy, comedy and socratic dialogue: the Symposium between the theatrical genres, Socrates between the beauty and the ugliness, E $\rho \omega \varsigma$ between the high and the low
\end{abstract}

\begin{abstract}
Diversas lecturas de algunos de los discursos del Banquete de Platón proponen que se trabaja en ellos con una mezcla entre lo trágico y lo cómico. Este artículo aúna esos resultados y suma elementos de análisis para construir una interpretación del diálogo que los integre en un todo y los ponga en relación con otros aspectos de la filosofía platónica. Sostenemos que en los discursos de Aristófanes, Agatón, Sócrates-Diotima y Alcibíades, y en el Banquete como totalidad, Platón opone distintas mezclas entre lo trágico y lo cómico a través de las cuales construye una postura sobre los géneros tradicionales. Desde esa perspectiva el diálogo socrático-platónico es el verdadero género $\mu \varepsilon \tau \alpha \xi \tilde{v}$, en una compleja analogía con la figura de Sócra-

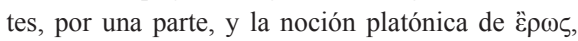
por otra.
\end{abstract}

Palabras clave: Platón; Banquete; filosofía; comedia; tragedia.
Various readings of some speeches of Plato's Symposium propose that within them the characters work with a mixture of the tragic and the comic. This article combines these results and adds elements of analysis to construct an interpretation of the dialogue that integrate the previous results into a whole and put them in relation to other aspects of Platonic philosophy. We argue that in the discourses of Aristophanes, Agathon, Socrates-Diotima and Alcibiades, and in the Symposium as a whole, Plato opposes various mixtures between the tragic and the comic through which he builds a position about traditional genders. Fron this point of view the socratic-platonic dialogue is the true $\mu \varepsilon \tau \alpha \xi \dot{v}$ genre, in a complex analogy with the Socrates figure, on the one hand, and the platonic notion of

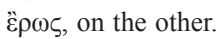

Key words: Plato; Symposium; philosophy; comedy; tragedy.

En el pasaje final del Banquete Sócrates dice a Agatón y Aristófanes que «es cosa del mismo hombre saber componer comedia y tragedia, y que quien con arte es autor de tragedias es también autor de comedias» (223d6-8). Esta 
afirmación ha llamado la atención de la crítica especializada, en la medida en que no existen noticias de que una misma persona haya compuesto en ambos géneros hasta época helenística. Se ha señalado frecuentemente que parece enrolarse en el típico argumento socrático respecto a la $\tau \dot{\chi} \chi v \eta$ : si hay una técnica/arte con la que escribir tragedia, debe posibilitar también escribir comedia. Un argumento similar le presenta Sócrates a Ion en el diálogo Ion al mostrarle que no es posible que tenga una $\tau \dot{\varepsilon} \chi v \eta$ para recitar a Homero, pues en ese caso también podría recitar con ella a Hesíodo u otros poetas. Notablemente, en República III 395a ss. Sócrates expresa lo contrario:

Sóc.- Mucho menos, por ende, [un mismo hombre] podrá ejercitar oficios de alto valor simultáneamente con la imitación de muchas cosas, por hábil que sea al imitar, puesto que incluso los dos tipos de imitación que parecen ser tan vecinos entre sí — como la comedia y la tragedia — no pueden ser practicados bien por las mismas personas.

Ad.- Sí, y tienes razón al afirmar que no pueden ser los mismos poetas los que creen ambas. (Platón 1986)

Esta respuesta de Adimanto hace innecesario el análisis detallado de la cuestión, por lo que se sigue adelante, pero resulta claro que en República no se aplica el argumento basado en la $\tau \dot{\chi} \chi v \eta$. En contraposición, en el Banquete Sócrates habla irónicamente ante dos interlocutores ebrios, incapaces de responderle adecuadamente. Sin embargo, como señala Mársico 2003, p. 45: «Las interpretaciones de este pasaje final son diversas y van desde lo anecdótico a la atribución a estas líneas de la clave exegética de toda la obra.» En efecto, la actividad de la crítica, cuando ha considerado importante esta afirmación socrática, ha sido la de buscar al autor de ambos géneros en el interior del Banquete, interpretando, entonces, ciertos discursos de sus personajes desde el punto de vista del género discursivo y relacionándolos con la comedia, la tragedia, e incluso el drama satírico. Eso mismo haremos aquí, ya que consideramos que, en efecto, la cuestión del género de los discursos está no solo presente en el Banquete, sino también que a través de ella puede leerse una dimensión del diálogo que ha sido generalmente soslayada. Propondremos que el Banquete contiene en su interior un discurso sobre el diálogo socrático-platónico definido como un tipo particular de mezcla entre la tragedia y la comedia - lo que en última instancia remite a la categoría central de lo serio-cómico-, y que los discursos de Aristófanes, Agatón, SócratesDiotima y Alcibíades están construidos con diferentes tipos de mezcla entre 
lo cómico y lo trágico, resultando la que está en la base del discurso de Sócrates-Diotima aquella que el diálogo propone como óptima, y que está también en la base del Banquete como totalidad. Consideramos pertinente sumar elementos de análisis y realizar un recorrido por algunas interpretaciones de estos discursos, que aportarán argumentos a la demostración de nuestra hipótesis.

\section{BREVE ESTADO DE LA CUESTIÓN Y ANÁLISIS DE ALGUNOS DISCURSOS:} IDENTIFICANDO LAS PIEZAS DEL ROMPECABEZAS

Posiblemente fue Dover 1966 quien potenció la discusión con respecto al género del discurso de Aristófanes al proponer que se trata no de una comedia, como hubiera sido esperable, sino de una historia con carácter de «unsophisticated, subliterate folklore» (p. 45). Dover propuso que Platón presenta a través de la figura de Aristófanes ciertos elementos representativos de la cultura popular que, siendo capaz de un cierto tipo de бopía, no puede estar a la altura, sin embargo, del tipo de saber encarnado por la filosofía. Por ello, considera que este discurso es genéricamente cercano al de una fábula como las de Esopo, esto es, un relato anclado a lo particular que apunta a una conclusión o saber de orden moral.

Rodríguez Adrados 1969 retoma el análisis de Krüger 1948 y señala que Aristófanes hace "comedia trágica» (p. 6). En efecto, entre otros elementos su discurso es trágico principalmente por la v̋ßpı de los antiguos seres dobles al intentar traspasar los límites del ámbito divino, motivo por el cual son castigados por Zeus, dando origen a la forma actual de la raza humana. El discurso de Aristófanes presenta un paso de la dicha a la desdicha $(\pi \varepsilon \rho ı \pi \varepsilon ́ \tau \varepsilon 1 \alpha)$ motivado por un acto excesivo para con los dioses y tiene, por ende, la evolución narrativa típica de una tragedia. Culmina, además, con el llamamiento a la mesura con el que finalizan muchas tragedias griegas.

Por otra parte, al referirse a la hipótesis de Dover, Rodríguez Adrados establece que los elementos cómicos de este discurso no tienen por qué ser considerados secundarios:

El tema de la perfección original del mundo, luego turbada de algún modo, es un tema cómico frecuentísimo ... Pero este tema del paraíso perdido se encuentra en realidad en toda la comedia: siempre hay que eliminar un obstáculo que nos devuelva a una felicidad pasada, aunque no se localice en la Edad 
de Oro...El héroe cómico elimina precisamente ese obstáculo y en cierto modo, la antigua felicidad es reconstruida: las aves se imponen a dioses y hombres, Pluto recobra la vista, se hace la paz, Cleón es derrocado, Esquilo es devuelto a la tierra, es quemada la escuela de Sócrates. No hay comedia conservada o conocida de algún modo de la que no pueda trazarse este esque-

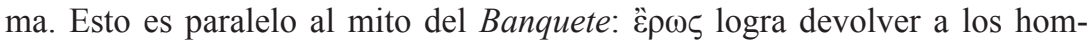
bres, aunque sea por momentos, a la felicidad original. (pp. 10-11.)

Este aspecto distingue al discurso aristofánico del género trágico. La concepción que de ês $\omega \varsigma$ tiene la tragedia griega lo define como una fuerza con agente divino que provoca un estado pasajero de enfermedad, locura o ceguera en el cual los personajes no actúan «razonablemente» y cometen errores que desencadenan sus propias desgracias ${ }^{1}$. Esta concepción encuentra su expresión en algunos pasajes frecuentemente citados para ejemplificarla: el himno a Eros de la Antígona de Sófocles — anterior al Banquete y que Platón, es de suponer, no ignoraba-, o algunos versos puestos en boca de Fedra por

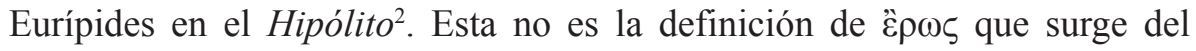
discurso de Aristófanes: allí a partir de él se recupera la antigua naturaleza perdida, quedando opuesto êp $\omega \varsigma$ a ű $\beta \rho ı \varsigma$. Es un elemento de desmesura lo que

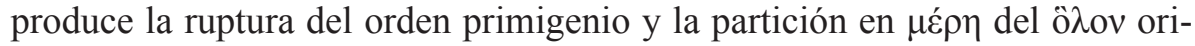
ginal. Estas partes combinadas, que son asociadas al sol, la luna y la tierra, configuran tres tipos de parejas marcadas por la pérdida y la carencia. Esta situación desastrada de los hombres sólo puede redimirse mediante ề $\omega \zeta$,

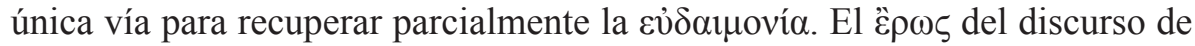
Aristófanes parece coincidir mejor, como dice Rodríguez Adrados, con los aspectos cómicos del discurso ${ }^{3}$. Esto significa que, así como hay elementos que claramente lo vinculan a una tragedia, no estamos en sentido estricto ante ella, en la medida en que no reproduce la ideología del género trágico res-

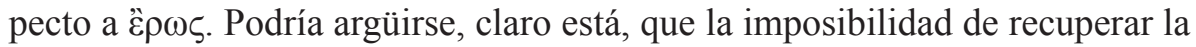
antigua naturaleza perdida surge como conciencia en el hombre precisamen-

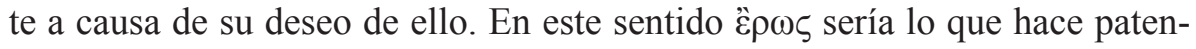

${ }^{1}$ Cf. Dodds 1980, Gill 1996, Padel 1997, entre otros.

${ }^{2}$ Cf. Sóf. Ant. 781 ss. y Eur. Hip. 391 ss.

${ }^{3}$ En ellos insiste también Suárez de la Torre 2002, al señalar que en el discurso aristofánico los dioses son presentados en funciones dignas de la comedia: Zeus como un cocinero que amenaza incluso con reducir a los hombres en lonchas; Apolo como un batanero, un zapatero trabajador de pieles, y, más adelante, Hefesto como un buen herrero (p. 86). 
te a los hombres su condición trágica, esto es, su condición de parte y su

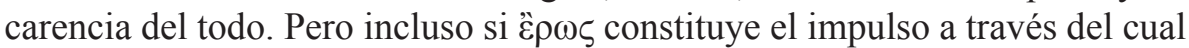
se les presenta a los hombres una condición trágica de su existencia, insistimos, no se trata de la concepción tradicional del género trágico.

Posteriormente, Soares 1999 sostuvo que se trata de una tragicomedia aportando una enumeración completa de los aspectos trágicos y cómicos del discurso, y luego (Soares 2009) que en el Banquete se presenta a Aristófanes como un poeta trágico.

Es buen momento para sumar a este recorrido interpretaciones anteriores: Robin 1908 señala que el discurso de Aristófanes es más poético que riguroso ( $\$ 71$, p. 49) y Bury 1909 lo denomina «comedy in miniature», y considera que se parodian en él ciertas teorías médicas de la época en la que se analizaban combinatoriamente, de acuerdo a la gestación, las posibilidades de sexo y orientación sexual de quienes nacían, así como la posición de Empédocles sobre la cuestión, concluyendo que «Aristophanes intended to satirize the theories of generation and of sex-evolution which were argued so solemnly and so elaborately by the confrères of Eryximachus» (p. XXXIII) ${ }^{4}$. Esta postura adquiere interés si se repara en que la supuesta mini-comedia trabaja en clave cómica temas serios presentes en su contexto. Algo muy similar hace el Aristófanes histórico en sus comedias, y de hecho en Nubes este ejercicio se realiza con la figura y las prácticas de Sócrates. En el Banquete da pie a esta satirización el contrapunto entre Aristófanes y Erixímaco que, algo antes, motivó el cambio de orden en la serie de oradores a causa del ataque de hipo de Aristófanes. Este ataque de hipo fue considerado por algunos una ridiculización de la figura de Aristófanes efectuada por Platón en venganza precisamente por el modo en que había sido presentado Sócrates en Nubes (Brochard 1926). Sin embargo, como señaló Eisner 1979, la venganza platónica parece hallarse más en el contenido del discurso de Aristófanes que en ese ataque de hipo: el relato aristofánico justifica la unión homosexual y la coloca a un nivel superior que la heterosexual, pues se detiene ampliamente en ella evidenciando su especial interés, la ensalza y argumenta en su defensa. Esto es muy alejado, según se colige de sus textos, de lo que pensaba el Aristófanes histórico sobre este punto.

Quienes no se refieren explícitamente a la cuestión del género de este discurso muestran también las vacilaciones que venimos señalando: Jaeger,

${ }^{4}$ Cf. también Robin 1938, p. LVII ss., O’Brien 2002. 
1933-47 lo llama «mito» (p. 575) y una posición intermedia, aunque posterior, es la de Nussbaum 1986, que lo denomina comedia (p. 176), mito (p. 174) y «comic myth» (p. 174).

Basados en este recorrido, podemos afirmar no solo que no existe acuerdo en la crítica especializada respecto al género del discurso de Aristófanes, sino también que resulta imposible enrolarlo taxativamente en una única formación discursiva; se trata, en todo caso, de un cierto tipo de mezcla: contiene los rasgos narrativos de una tragedia, pero en su concepción de Eros y su impronta popular hallamos caracteres distintivos de la comedia. Es posible, sin embargo, limitar la mixtura a estos dos géneros: a las críticas de Rodríguez Adrados a Dover puede sumarse que la fábula esópica es traída a colación por este último en relación con el tipo de sabiduría presente en lo popular, pero eso mismo se identifica con el género cómico. Algo equivalente puede decirse del tratamiento de este discurso como mito: elementos como la fuerza etiológica de lo narrado por Aristófanes se corresponden con una perspectiva propia de un mito, pero aquí nos encontramos ante un mito ya trabajado en la forma de la tragedia.

En esta relación peculiar entre forma y contenido hay una fuerte referencia a Nubes: una de las particularidades de esta comedia es que parece tener el desarrollo narrativo típico de una tragedia. Cavallero 2006 ha explorado esta cuestión en detalle, proponiendo que Nubes «no es una tragicomedia o un híbrido sino que, tanto por sus componentes, su héroe, sus recursos y actitudes, Aristófanes la expone como ejemplo de $\tau \rho v \gamma \omega \delta i ́ \alpha$, es decir, de una tragedia en disfraz de comedia» (p. 89). En efecto, Cavallero analiza exhaustivamente la cuestión y muestra cómo están presentes en Nubes diversos rasgos trágicos como la üßpıৎ de Estrepsíades ${ }^{5}$, su $\dot{\alpha} \mu \alpha \rho \tau i ́ \alpha$ al no prever los peligros de darle a su hijo herramientas que podían ser utilizadas en contra suya, y la $\pi \varepsilon \rho \iota \pi \varepsilon ́ \tau \varepsilon 1 \alpha$, dado su final no solo atípico para el género cómico, sino directamente trágico, sin que por todo esto se abandonen la estructura formal y el estilo cómicos. Si retomamos la caracterización que veníamos haciendo del discurso de Aristófanes en el Banquete, resulta claro que la expresión «trage-

${ }^{5}$ Cavallero menciona diversas conductas excesivas de Estrepsíades: su casamiento con una aristócrata y su deseo de vivir por encima de sus posibilidades; que pretenda, sabiéndose poco memorioso, acceder a las artes del lenguaje capaz de defender la verdad o de tergiversarla; que, instruido ya su hijo, desprecie al público (vv. 1201-1203); que acuse a las diosas Nubes de ser responsables de su situación (vv. 1452-1453); y que recurra a la violencia vengativa, amparado en el supuesto consejo de Hermes (vv. 1478 ss.). 
dia disfrazada de comedia» (p. 94) que Cavallero aplica a Nubes puede referirse stricto sensu al discurso aristofánico. La fuerte remisión a esta comedia desde el interior del Banquete plantea el marco en el cual se da la venganza platónica que mencionamos antes. Uno de los hombres capaces de componer tragedia y comedia a la vez, de acuerdo a la afirmación de Sócrates que adoptamos como punto de partida, es Aristófanes.

La mezcla entre comedia y tragedia ha sido analizada también en relación con el discurso que pronuncia Alcibíades tras irrumpir borracho en la reunión, irrupción que ha sido caracterizada como la del mismo Dioniso (Rowe 1998). En apariencia, este ingreso produce un cambio en el tema, que se transforma de Eros en Sócrates. Se ha propuesto que su discurso es un drama satírico (Sheffield 2001, Usher 2002); a lo que apunta una afirmación de Sócrates: «... pero no me pasaste inadvertido, sino que ese drama tuyo satírico y silénico resultó visible.» (222d3-4) El drama satírico se basaba en una mixtura entre comedia y tragedia representada en competencias como las Grandes Dionisias tras la puesta en escena de las tres tragedias de cada autor. Hay algunos rasgos que parecen ser típicos del género: la presencia de sátiros - la relación entre Dioniso y el drama satírico es más explícita que en la tragedia o la comedia - y un tipo de mixtura particular entre lo serio y lo risible; su intención sería mostrar los temas serios que antes ha tratado la tragedia en una nueva clave cómica, con un nuevo espíritu que produce, mediante la sátira, un distanciamiento del espectador. Estos rasgos están presentes en el discurso de Alcibíades: allí se compara a Sócrates con sátiros -Marsias- y estatuas de silenos — de ahí que Sócrates lo llame también drama silénico - y se presenta una imagen en la que se ridiculiza aquello que está presente en Sócrates y que momentos antes, en el discurso SócratesDiotima, se consideró seriamente. Visto así, el discurso Sócrates-Diotima propone que Sócrates es encarnación de una cierta noción de êp $\rho \varsigma$ y Alcibíades retoma la misma línea pero presentándola en una perspectiva satírica. $\mathrm{Su}$ discurso explora la dualidad presente en Sócrates — la misma de sus $\lambda$ ó tiene un aspecto feo, torpe, anda descalzo, pero está lleno de tesoros en su interior. Asimismo, sus $\lambda$ ó $\gamma o r$ parecen referirse a cuestiones contingentes, pero contienen sabiduría ${ }^{6}$. El Sócrates que describe Alcibíades se parece más al personaje típico de una comedia que al de una tragedia, pero tanto en su interior como en el interior de sus $\lambda$ ófor nos topamos con asuntos serios,

\footnotetext{
${ }^{6}$ Cf. Rodríguez Adrados 1992.
} 
elevados, más apropiados como temas de tragedia que de comedia. Del discurso de Alcibíades puede decirse entonces lo mismo que dijimos del de Aristófanes: es una cierta mezcla entre comedia y tragedia. Estamos, no obstante, ante otra posibilidad de combinar estos dos elementos que en esta ocasión coincide con un género existente, el drama satírico.

Si se siguen las líneas trazadas por Krüger 1948, el discurso de Agatón, en contraposición con el de Aristófanes, puede considerarse una «tragedia cómica». Generalmente se han enfatizado en relación con este discurso los elementos de estilo y construcción propios de un sofista, dada la mención inmediatamente posterior de Gorgias en boca de Sócrates (198c ss.), quien también menciona que lo dicho por Agatón es una apariencia de elogio y no un verdadero elogio (198e3 ss.). En esta dirección se ha interpretado también que Agatón diga, al terminar de hablar, que pronunció sus palabras con $\pi \alpha \iota \delta$ ó, además de mesurada $\sigma \pi \circ \delta \delta \eta ́$ cuando solo esto último es propio de un poeta trágico $(197 \mathrm{e} 5)^{7}$. Sin embargo — y más allá de que naturalmente se espera que Agatón pronuncie una tragedia, como de Aristófanes se esperaba una comedia-, existe un componente trágico en el modo en que suceden las cosas: cuando Agatón termina su discurso es aplaudido por todos, pero momentos después, por acción de Sócrates, debe aceptar ante esas mismas personas que lo aplaudían que su discurso carecía de sustento, esto es, se produce un cambio de suerte - una peripecia - ligado a la fama que acaba de reafirmar Agatón al pronunciar su elogio. Este cambio de suerte se combina con cierta $̋ ß \beta \rho \varsigma \zeta$ de Agatón antes de iniciar su discurso, ya que responde afirmativamente a la recriminación socrática de que no se avergüenza ante ellos por pertenecer a la masa, pero que lo haría si los considerara sabios (194c2 ss.): esa respuesta es su error trágico. De alguna manera, Agatón y su discurso son contracaras de Sócrates y el discurso Sócrates-Diotima: Agatón es joven y bello, su modo de hablar es atractivo e impactante, pero en su interior no hay verdad.

Al comenzar, Agatón establece que para realizar un elogio es necesario decir primero cuál es la naturaleza de aquello que se elogia y, luego, de qué clase de efectos es responsable. Este principio es puesto a salvo más tarde por Sócrates, que sin embargo afirma que el discurso de Agatón carece de

7 Es más escasa la bibliografía relacionada al discurso de Agatón que a otros aspectos del Banquete, pero en las diversas Introducciones, ya sea a traducciones o a ediciones del texto griego, se ha vuelto tradicional el juicio de que el discurso de Agatón es el de un sofista. 
verdad. Lo que se refuta en esa suerte de caída en desgracia de Agatón es el segundo principio presente en su encomio: «lo semejante se acerca siempre

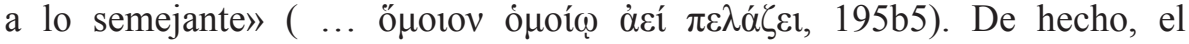
planteo socrático-platónico de que se busca aquello de lo que se carece está directamente enfrentado con este segundo principio. El primer principio es aceptable desde la perspectiva ontológica platónica, que procede siempre desde la causa hacia sus efectos. El segundo es problemático en diversos sentidos. Ante todo, no resulta claro qué significa allí 'siempre' (ảeí), ya que eventualmente podría tratarse a la palabra 'siempre' como si se tratara de la palabra 'solo': «Algunos especialistas leen siempre a Platón» podría querer decir que «frecuentemente leen a Platón» o que «solo leen a Platón (si leen) $\rangle^{8}$. No hay ningún motivo para pensar que esta ambigüedad pueda estar ausente en griego. Por otra parte, es relativamente fácil pensar qué quiere decir ő $\mu o t o \varsigma$ en la oración que enuncia el principio («si algo posee una propiedad y es semejante a otra cosa en cuanto a esa propiedad, esa otra cosa también posee esa propiedad»), pero no sucede lo mismo con «se acerca a». El verbo $\pi \varepsilon \lambda \alpha \dot{\zeta} \zeta \omega$ significa 'acercarse', 'aproximarse' sobre todo en sentido físico: 'acercarse a un lugar o un evento'. Pero, ¿qué quiere decir que Eros se acerca a algo? O bien significa que se acerca en ese sentido literal, físico, del verbo, o bien estamos ante un uso metafórico. Analicemos, para poder seguir adelante, cómo Agatón organiza su discurso:

— afirma que Eros es el más feliz de los dioses, por ser el más hermoso y el mejor (195a $8 \mathrm{ss}$.);

- señala que una de las causas es que es el más joven y argumenta a favor de ella, mediante el segundo principio (195b ss.);

- afirma que otra causa es que es delicado y argumenta (195c9 ss.);

- afirma que otras causas son su flexibilidad o figura bien proporcionada y la belleza de su tez, y da breves argumentos (196a ss.);

- da por finalizada la parte de su discurso referente a la belleza de Eros e inicia la dedicada a su virtud (196b ss.);

- afirma que una causa es que no comete ni es objeto de injusticia, y argumenta a favor de ella (196b3 ss.);

${ }^{8}$ Es decir que en el segundo principio 'siempre' podría equivaler a un cuantificador universal, dándole el sentido a) para todo $x$ e $y$, si $x$ e $y$ son semejantes, entonces $x$ se acerca a $y$; o bien podríamos estar también ante b) para todo $x$ e $y$, si $x$ se acerca a $y$, entonces $x$ es semejante a $y$, si 'siempre' equivale a 'solo'. 
- afirma que participa de la mayor templanza y argumenta a favor de ello (196c8 ss.);

- afirma que es valiente y argumenta a favor de ello (196d5 ss.);

- afirma que es sabio y argumenta a favor de ello (196d5 ss.);

- concluye con un final de impactante vuelo poético (197c).

Expuesta así la estructura del discurso, lo dicho en relación con el segundo principio parece exagerado: su influencia estaría acotada solo a una pequeña parte de lo que dice Agatón. Sin embargo, demostraremos que la influencia del segundo principio es mayor.

Para establecer que Eros es el más joven de los dioses Agatón dice que huye de la vejez, que la odia, y que no se le aproxima. Luego, enuncia el segundo principio y explica que, cuando Eros nació, finalizó el imperio de la necesidad: los demás dioses ya existían y, por ende, son mayores. Tomemos el primer argumento: lo que se afirma es 1) si $x$ huye de la vejez, entonces $x$ es joven; 2) si $x$ odia la vejez, entonces $x$ es joven y 3 ) si $x$ no se le aproxima a la vejez, entonces $x$ es joven. Si a la afirmación 1) le aplicamos la versión del segundo principio en la que àcí significa 'siempre' en el sentido de 'frecuentemente', resulta entonces que si Eros huye de la vejez, entonces Eros se acerca frecuentemente a los jóvenes —asumiendo que «viejo» y «joven», «huye» $\mathrm{y}$ «se acerca» son pares de contradictorios- - pero de esto no se sigue que los jóvenes y Eros sean semejantes. Confiemos en la capacidad argumentativa de Agatón y pensemos que en el segundo principio ảcí debe ser entendido como 'solo'. Resulta entonces que si Eros solo se acerca a los jóvenes, entonces es semejante a ellos en juventud, por lo que Eros es joven. Lo mismo se aplica a 2) y 3 ).

La primera conclusión es que en el segundo principio àcí debe ser equivalente a 'solo'. Considerando esta versión del segundo principio, desde el punto de vista lógico la argumentación de Agatón es válida.

Teniendo presente esto último, avancemos hacia los argumentos a favor de la delicadeza de Eros: Agatón se apoya en una cita de Homero: Ate es delicada porque no se acerca al suelo, es decir, porque no anda sobre lo duro, sino sobre lo blando: el verbo que se usa esta vez es $\pi \imath \lambda v \alpha ́ \omega$ 'acercarse', con un sentido típicamente ligado a la cercanía física, como sucedía con $\pi \varepsilon \lambda a ́ \zeta \omega$. A continuación, señala que Eros 1) no anda sobre la tierra ni sobre cráneos (cosas duras); 2) anda y habita sobre las cosas más blandas, los caracteres y almas de dioses y hombres, e incluso, si tropieza con un alma cuyo temperamento es duro, se marcha. Por lo tanto, concluye Agatón, al estar en contac- 
to con las cosas más blandas, Eros es blando. Si analizamos esto a la luz de lo anterior, surge que es válido siempre y cuando «blando» y «duro» sean contradictorios y se siga aplicando el segundo principio. Aquí «andar», «habitar» y «estar en contacto» son sinónimos de «acercarse». Por lo tanto, el principio de que lo semejante se acerca siempre a lo semejante sigue siendo necesario en esta parte de la argumentación.

A continuación, Agatón argumenta respecto a la flexibilidad y belleza de tez de Eros. Con respecto a la flexibilidad, señala que si no fuera flexible no sería capaz de entrar y salir por primera vez de las almas inadvertidamente, ni de envolverlas por todos lados y que es flexible porque es elegante, y que es elegante porque todos dicen que entre Eros y la deformidad existe mutuo antagonismo. Esta parte de la argumentación no depende del segundo principio.

En cuanto a la belleza de su tez, el argumento es que Eros no se asienta sobre cosas marchitas, sino que se posa y asienta sobre lugares floridos y perfumados. Evidentemente, se recurre de nuevo al segundo principio.

Luego se inicia la parte del discurso dedicada a las virtudes de Eros. En esta sección no parece que sea necesario suponer el segundo principio para sostener la argumentación; su influencia se concentra en la demostración de que Eros es el más hermoso y el mejor de los dioses. La refutación posterior de Sócrates se concentra precisamente en este aspecto, dejando de lado lo dicho por Agatón sobre las virtudes, más allá de que esa escisión entre virtudes y belleza es, por cierto, inaceptable para la filosofía platónica.

Debe notarse que, si se trabaja con el principio de que lo semejante se acerca a lo semejante, y se deduce, por ejemplo, que Eros es joven porque solo se acerca a los jóvenes, o que es blando porque solo habita en y entre cosas blandas, que o bien se llega a conocer cuál es la naturaleza de Eros a través de sus efectos, o bien se trabaja bajo la convicción de que Eros no es la causa de la juventud o la blandura de las cosas. Si se piensa que las cosas blandas son blandas a causa de Eros, entonces no se puede concluir que Eros es blando porque se acerca a ellas, a menos que se contradiga el primer principio del discurso: primero la naturaleza, luego sus efectos. Por lo tanto, o bien el segundo principio contradice al primer principio, en la medida en que para conocer cuál es la naturaleza de Eros se analizan sus efectos y, a partir de ellos, se deduce su naturaleza, o bien Eros no es el causante de, por ejemplo, la juventud y la delicadeza de aquellas cosas a las cuales se acerca. En el caso de la juventud, Agatón suma otro argumento: Eros nació después. 
Esto significa que la posibilidad de ser joven existía antes del nacimiento de Eros, y sugiere que Eros no es para Agatón el agente de la juventud, la delicadeza, etc. Si asumimos entonces que Eros no es el causante de aquellas cosas a las que se acerca, sucede que está ausente del discurso todo aquello que tiene que ver con los efectos de Eros, que sin embargo había sido prometido al comienzo. Esta ausencia sorprende en un discurso tan bien estructurado: hay que considerar la posibilidad de que la última parte, que describimos antes como un remate con gran vuelo poético, sea la que expone los efectos de Eros. En efecto, en esa última parte de su discurso Agatón parece resumir los dones de Eros a los hombres.

Ahora bien, supongamos que se quiera encomiar a Eros y se disponga del segundo principio. En ese caso, basta con pensar cualquier predicado que se quiera adscribir a la naturaleza de Eros y postular que Eros se acerca a algo que posea esa propiedad. Por ejemplo, se podría argumentar que Eros es un mamífero porque se acerca a los mamíferos, y ocultar el truco argumentativo llevando más lejos la metáfora: «a mamíferos como los osos panda y los corderitos Eros los acaricia constantemente, y a los que se alimentan de otros modos, como tienen pelajes ásperos, les huye». El segundo principio es el elemento de $\pi \alpha \iota \delta$ ó del discurso de Agatón, que evidentemente, como mencionamos supra, remite a un juego sofístico. Sin embargo, en la ironía, llena de v̋ßpıs, de decir al finalizar que se acaba de actuar con $\pi \alpha 1 \delta i \alpha$, hay una burla de Agatón dirigida a los otros comensales, burla que precisamente es castigada por Sócrates. Esa burla irónica está presente también en los constantes superlativos que usa para describir lo que propone como naturaleza de Eros y en la cantidad exagerada de rasgos positivos que suma haciendo uso de un procedimiento con el que se podría predicar, en realidad, casi cualquier cosa. Si se hace caso de esta peculiaridad del discurso de Agatón, resulta no solo que hay allí una remisión a la sofística, sino también una fuerte crítica basada en la soberbia que queda implicada en la actitud del sofista, que llevada al extremo constituye una burla a sus interlocutores.

El contenido del discurso de Agatón remite sin duda a un juego sofístico, pero en sus actitudes y en la de sus interlocutores hay algo más. El discurso de Agatón también posee algo de trágico y de cómico, aunque, nuevamente, la mezcla está organizada de otro modo: es trágico lo que le sucede cuando se enfrenta a la verdad, y agresivamente cómico para con quienes escuchan. Este tipo de agresividad, si se lee comedia aristofánica, está presente en el género cómico, lleno de ironías y burlas a ciertos sectores e incluso, en oca- 
siones, al público mismo ${ }^{9}$. Mediante ellas se desestima a un oponente o a quien escucha ocultando el modo tramposo en que se razona para lograr las conclusiones que se desean. Posiblemente esta burla constituya uno de los momentos en que con más fuerza se hace presente el tinte agonístico tantas veces señalado del Banquete. A través de ella se critica no solo a la sofística, sino también a la comedia y a la carencia de contenidos de la última tragedia, cuyo estilo tendía a sentirse como emparentado con el de los sofistas - particularmente en el caso del Agatón histórico, que parece haber sido amante de los juegos fónicos ${ }^{10}$ - . No parece casual que la mención burlesca de Gorgias que hace Sócrates inmediatamente después haga referencia simultáneamente también a la Gorgona, un ser proveniente del mundo de los mitos, esto es, de la épica y la tragedia.

En un artículo que toca de manera directa la cuestión de la afirmación socrática del final del Banquete, Clay 1994 ha propuesto que «Plato is the tragic and comic poet of the Symposium, and the object of his imitation is Socrates, who moves between the sublime and the ridiculous.» (p. 46) Clay muestra cómo Platón combina en el diálogo socrático-platónico elementos de la tragedia y de la comedia, cosa que se aplica bien al Banquete: allí se presenta la reunión en la casa de Agatón como si se tratara de un episodio mítico, a través de una cadena de transmisores que lo repiten de memoria, y suceden acontecimientos graciosos, como el modo en que Sócrates se detiene y hace llegar solo a Aristodemo, quien no había sido invitado, a la casa de Agatón. También, según se mencionó, hay en él una venganza por el modo en que Aristófanes había tratado a Sócrates en Nubes - y la venganza es algo propio de la tragedia-, o un divertido contrapunto entre Erixímaco y Aristófanes por el ataque de hipo de este último. Finaliza, como a veces lo hace la comedia, en borrachera, pero contiene momentos serios, por ejemplo cuando se refuta duramente a Agatón por no decir la verdad. La situación misma de banquete constituye en la Antigüedad un contexto típico de la presencia simultánea de lo serio y de lo cómico, como puede leerse, por ejemplo, en los diversos ejemplos que presenta la épica ${ }^{11}$. Es visible, por otra parte, que el discurso SócratesDiotima funciona en el Banquete como representante del género diálogo socrático, y de hecho contiene la misma mixtura de elementos que mencionamos

\footnotetext{
9 Cf. Nubes 1200 ss., entre otros.

10 Cf. Mitscherling 1985.

${ }^{11}$ Cf. también Robin 1938, pp. XII-XVII.
} 
para la totalidad del diálogo: los serios y elevados, como la mención de la puesta a salvo de un pueblo de la peste, o el relato de un mito - el de Poros y Penía - y los cómicos, como una broma dirigida a Aristófanes realizada mediante un anacronismo. Como Sócrates, es $\varphi \alpha \tilde{\lambda} \lambda$ o en su aspecto, pero trata temas $\sigma \pi$ ov $\delta$ ĩos. Rescata de la comedia un lenguaje común, una recuperacion de lo oral ${ }^{12}$, pero los temas que trata son propios del género trágico. El discurso de Sócrates-Diotima es también una mezcla entre lo trágico y lo cómico, otra posibilidad más de combinación de estos elementos.

\section{HiPÓtesis: ARMANDO EL ROMPECABEZAS}

Los discursos de Aristófanes, Agatón, Sócrates-Diotima y Alcibíades pueden caracterizarse como mezclas de distinto tipo entre lo trágico y lo cómico, e incluso el diálogo socrático tal como lo concibe Platón cae dentro de este tipo de mixtura. Ante todo, esto permite comprender la razón del ataque de hipo de Aristófanes: parece ser un modo de modificar el orden de los oradores de manera tal que todos aquellos que realicen discursos caracterizables en términos de mixtura entre lo serio y lo cómico queden reunidos ${ }^{13}$. En esta parte del Banquete lo que se tematiza entre líneas, al tiempo que se hacen discursos sobre Eros, en un paso menos abrupto pero de algún modo similar al que sucede en el Fedro, es la cuestión de los géneros discursivos. Esta cuestión va más allá de un análisis con el objeto de enrolar un discurso en mayor o menor grado en un género, ya se trate del trágico o el cómico, o de establecer cómo está cocinada la mezcla: lo trágico y lo cómico aparecen aquí como una de las oposiciones sobre las que en el Banquete se insiste constantemente: lo anciano vs. lo joven, lo elevado vs. lo vulgar, lo ordenado $v s$. lo desordenado, lo serio vs. lo risible, el amante vs. el amado, lo celeste vs. lo popular, lo honroso vs. lo vergonzoso, etc. Sin embargo, esta oposición en particular, proponemos, tiene un status diferente al de las otras. El orden de los oradores ha quedado organizado de manera tal que, quienes hablan a partir de Aristófanes, se identifican con una actividad ligada indisolublemen-

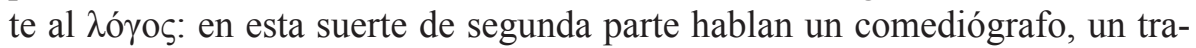

12 Cf. Wieland 1999.

${ }^{13}$ El traductor de Gredos, en su nota al pie 57, resume las diversas posiciones con respecto al episodio del hipo aristofánico, algunas de las cuales coinciden en que su sentido es modificar el orden de los oradores. 
gediógrafo, un filósofo y un político. En lugar de satisfacer las expectativas del lector, que de manera inevitable conoce la identificación de cada uno de estos personajes con un tipo particular de $\lambda$ ó $\gamma o s$, cada uno de ellos produce una mixtura diferente entre comedia y tragedia.

Aristófanes habla de recuperar la antigua integridad perdida. Esto, sin embargo, no puede realmente llevarse a cabo, salvo por medio de una extraña intervención divina como la que plantea en su discurso (192d) —lo que además produciría la recuperación de esa integridad solo en un caso particular-. La mixtura entre tragedia y comedia que produce podría tener la intención de salvar la distancia entre estos opuestos volviendo a un origen en el que se encontraban todavía indiferenciados. Sin embargo, este discurso no es capaz de superar la oposición entre tragedia y comedia, sigue dependiendo de ellas para constituirse en un híbrido: así como no puede volverse el tiempo atrás para recuperar verdaderamente la antigua integridad perdida, tampoco es posible remontar la historia para recuperar un supuesto género - $\mathrm{y}$ la misma palabra que se usa en el discurso de Aristófanes para el sexo de los seres dobles, $\gamma \varepsilon \dot{v} v o \zeta$, es la que se utiliza en griego para el género literariodionisíaco primigenio anterior a la escisión entre comedia y tragedia. No en vano la broma que Sócrates-Diotima dedica a Aristófanes está basada precisamente en un anacronismo.

Agatón afirma que lo semejante se acerca siempre a lo semejante y ese principio le es útil para identificar todo polo positivo de una oposición éticamente valorativa con Eros. Al mismo tiempo, su discurso, estructurado como el de un sofista, cae, por falso, en una tragedia, y tiene de la comedia la burla. No es capaz, por supuesto, de superar la oposición entre lo trágico y lo cómico, en la medida en que carece de verdad, se constituye a través de un juego que cierra al discurso sobre sí y lo priva de referencia a lo real.

El discurso de Sócrates-Diotima representa la mixtura verdaderamente superadora de la oposición entre comedia y tragedia, y esto se proyecta sobre

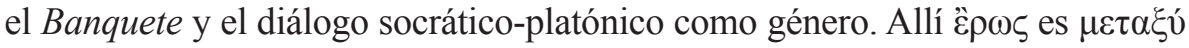
y adquiere entidad precisamente no identificándose con el polo de ninguna oposición, sino siendo diferente a todos $\mathrm{y}$, por lo tanto, además, no opuesto a nada. Del diálogo platónico-socrático puede afirmarse lo mismo: no es ni trágico ni cómico, en la medida en que, si bien contiene elementos tanto de la tragedia como de la comedia, no se identifica con ninguna de ellas. Es una combinación entre lo serio y lo risible, lo elevado y lo bajo, a través de la cual se puede alcanzar la verdad, un tipo de $\mu$ í $\mu \eta \sigma ı$ que no produce la apa- 
riencia de un elogio, sino un elogio propiamente dicho, lo que ocasiona que

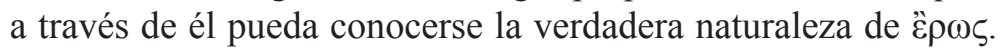

Alcibíades, el representante de la política, presenta un drama satírico y, al

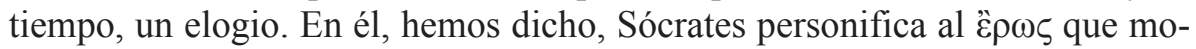
mentos antes se ha descrito en el discurso de Sócrates-Diotima. Alcibíades, como se destaca en el inicio de su discurso, dice la verdad, aunque, debe notarse, esa verdad queda puesta bajo la vigilancia de quien está siendo elogiado. En términos pragmáticos, su elogio intenta convencer a los demás de que no se acerquen a Sócrates, ya que no obtendrán ningún resultado, lo que al mismo tiempo le deja el camino libre para continuar con sus intentos amorosos. La mezcla entre lo cómico y lo trágico le sirve para elogiar y al tiempo conquistar un territorio, no tiene ningún valor en sí más que esta utilidad. $\mathrm{Su}$ autor no puede, en realidad, pensar en los términos abstractos en que han elaborado sus discursos los otros: esta mixtura responde por lo tanto a esos motivos pragmáticos y no constituye ninguna superación verdadera de la oposición entre lo trágico y lo cómico.

Como se observa, cada discurso tiene una intención: la de Aristófanes tal vez sea satirizar a Erixímaco y las teorías médicas de la época; la de Agatón, pronunciar el mejor elogio y aparecer como superior a los demás; la de Sócrates-Diotima, afirmar verdades sobre ê $\rho \omega \zeta$; la de Alcibíades, acercarse a Sócrates al tiempo que aleja de él a sus oponentes. Estas intencionalidades producen, en última instancia, la mezcla particular entre lo trágico y lo cómico en cada discurso. En una concepción de lo sensible como la platónica probablemente no puedan más que considerarse mezclas, híbridos entre lo elevado y lo bajo que nunca representan por completo alguno de estos polos. Todos estos discursos están signados por su pertenencia a lo serio-cómico, lo spoudogéloion $^{14}$. La mezcla que realiza quien tiene interés en la verdad constituye el género discursivo propio de la filosofía.

Una de las cosas que dice el Banquete es que el diálogo socrático tal como lo concibe Platón es la única opción posible para el filósofo, construyendo una

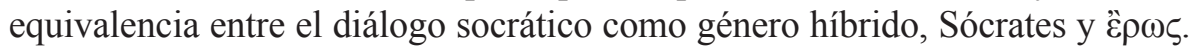
Esta equivalencia funciona en tres niveles distintos de explicitación e involucra porciones diferentes del texto: para conocer la postura de la filosofía sobre

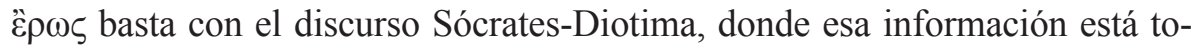
talmente explícita. Si se suma el discurso de Alcibíades, puede completarse la

${ }^{14}$ Cf. Giangrande 1972. 
analogía entre êp $\omega \varsigma$ y Sócrates, de fácil interpretación, aunque no totalmente explícita. Si se incorporan, a su vez, los discursos de Agatón y Aristófanes y

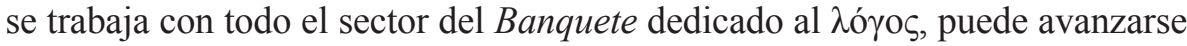
hacia el nivel donde el diálogo socrático-platónico equivale a Sócrates y ê $\rho \omega \zeta$, respectivamente, en los niveles anteriores, pero ahora la interpretación es trabajo más complejo; lo que se dice es menos explícito. El discurso SócratesDiotima opone una concepción de êpos ante otras; del de Alcibiades, obtene-

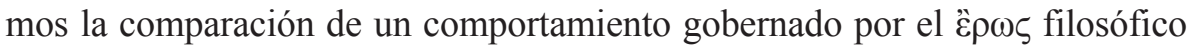
con otros - un comportamiento $\mu \varepsilon \tau \alpha \xi \tilde{v}$, por cierto, ya que Sócrates, por ejemplo, no puede definirse ni como amante ni como amado-; al tomar en cuenta también los discursos de Agatón y Aristófanes, observamos la superioridad de un discurso $\mu \varepsilon \tau \alpha \xi u ́$ frente a otros que bien pueden ser en cierto sentido «intermedios», pero no están preocupados por la verdad: en primer lugar, la naturaleza de ê $\rho \omega \zeta$, luego sus efectos y sus dones a los hombres.

Por supuesto, este discurso que contiene el Banquete acerca del diálogo socrático-platónico no deja de ser una suerte de propaganda de los medios de expresión de la filosofía y de la filosofía misma frente a otros géneros discursivos, pero hay también en él una apropiación no inocente de procedimientos cómicos y trágicos que en el Banquete, así leído, se critican, en una suerte de táctica de ocultamiento: es harto evidente, por ejemplo, que, a pesar de la fuerte impugnación de la postura de Agatón, Sócrates en muchos casos hace uso de un tipo de ironía similar para con sus interlocutores. La comedia, por otra parte, trabaja fuertemente con la autorreferencialidad que tan importante es luego en toda la literatura occidental. La ruptura de la ilusión teatral y la remisión a sus propios mecanismos de funcionamiento textual son características centrales del estilo aristofánico. Este es otro rasgo que Platón se apropia en el Banquete al generar una autorreferencialidad crítica para con los otros géneros. En este sentido, quizá el compromiso con los recursos de la comedia que tenga este diálogo sea mayor que el que tiene en relación con la tragedia: en la apropiación de este mecanismo se funda todo lo que hemos dicho.

Hay que decir también, en cuanto a la tragedia, que la asimilación platónica persigue la conquista de un terreno discursivo que tradicionalmente le pertenecía a este género. El lugar en que positivamente se reflexionaba y se construía un discurso sobre los valores en Atenas era la tragedia, heredera de la épica y con la posibilidad de involucrarse menos en los problemas de la vida práctica que la comedia. Evidentemente, no puede afirmarse que la comedia aristofánica no haya trabajado en el terreno de la ética, pero la construcción 
de valores y la reafirmación de las creencias, por así decir, oficiales de Atenas, caen del lado de la tragedia. El proyecto de la filosofía platónica en todas sus etapas criticó el modo en que los atenienses construían sus valores, y eventualmente propuso otro modo de definirlos. Incluso en los diálogos tempranos la pregunta socrática suele apuntar a desmentir que los ejemplos, esto es, los casos particulares de aparición de algún comportamiento éticamente valorable como la valentía o la piedad, tengan alguna utilidad para definir esos valores. La fuente de «ejemplos» propuestos como modelos o anti-modelos de comportamiento ético de la cultura ateniense son precisamente los géneros épico y trágico. Como se observa, en el marco de un proyecto como este Platón no podía más que enfrentarse con la tragedia y disputar su territorio. Este enfrentamiento es explícito en República II, III y X, pero recorre de manera implícita buena parte de su obra. Un género nuevo como el diálogo socrático, por otra parte, no podía surgir de la nada: evidentemente hereda sus procedimientos de los géneros previos. De ahí la operación platónica de apropiarse de los mecanismos narrativos de la tragedia y, al tiempo, re-significarlos y oponerse a ella, que ha sido detectada en diversos diálogos ${ }^{15}$.

Por supuesto, la cuestión dista de finalizar aquí. Sin embargo, a pesar de lo arriesgado de algunas opiniones y de la provisionalidad de algunos argumentos, este recorrido permite entrever que hay una dimensión del Banquete no del todo comprendida que necesita ser revisada. Este tipo de acercamiento, por otra parte, aporta elementos para la construcción de una filosofía platónica en contexto, algo de cuya necesidad se viene tomando conciencia desde hace algunos años ${ }^{16}$.

\section{BIBLIOGRAFÍA}

Brochard, V., 1926: «Sur le Banquet de Platon», Etudes de philosophie ancienne et de philosophie moderne 74, Paris, pp. 89-90.

Cavallero, P., 2006: «Trygoidia: La concepción trágica de Nubes de Aristófanes», Emerita. Revista de Lingüistica y Filología Clásica 74, 1, pp. 89-112.

Cavallero, P., et al. 2008: 'Nubes'de Aristófanes. Edición bilingüe con introducción, notas y apéndice, Universidad de Buenos Aires, Facultad de Filosofía y Letras, Instituto de Filología Clásica.

15 Cf. por ejemplo Harman 1986, Nightingale 1992, Howland 2008 o Trivigno 2009.

${ }^{16}$ Cf. Clay 1994, Nightingale 1995, Kahn 1996 entre otros. 
Clay, D., 1975: «The Tragic and Comic Poet of the Symposium», Arion New Series 2, 2, pp. 238-26.

Clay, D., 1994: «The origins of the Socratic dialogue», en Waerdt, P. (ed.), The Socratic Movement, Nueva York, Cornell, pp. 23-47.

Dodds, E., 1980: Los griegos y lo irracional, Madrid, Alianza Editorial.

Dover, K., 1966: «Aristophanes' Speech in Plato»s Symposium», The Journal of Hellenic Studies 86, pp. 41-50.

Dover, K. (ed.), 1980: Symposium, CUP.

Gill, C., 1996: Personality in Greek Epic, Tragedy, and Philosophy: The Self in. Dialogue, Oxford Clarendon Press.

Harman, J. D., 1986: «The Unhappy Philosopher: Plato's Republic as Tragedy», Polity 18, 4, pp. 577-594.

Howland, J., 2008: «Plato»s Apology as Tragedy», The Review of Politics 70, 4, pp. 519-546.

Eisner, R., 1979: «A case of Poetic Justice: Aristophanes' Speech in the Symposium», The Classical World 72, 7, pp. 417-419.

Giangrande, L., 1972: The Use of Spoudaiogeloion in Greek and Roman Literature, La Hague-Paris.

Jaeger, W., 1933-47': Paideia: los ideales de la cultura griega, trad. J. Xirao 1990, México, FCR.

Kahn, Ch., 1996: Plato and the Socratic Dialogue: The Philosophical Use of a Literary Form, New York, CUP.

Krüger, G., 1948: Einsicht und Leidenschaft. Das Wesen des platonischen Denkens, Frankfort, V. Klostermann.

Mársico, C., 2003: «Introducción general y estudio preliminar», en Platón, Banquete, Buenos Aires, Altamira.

Mársico, C., 2010: Zonas de tensión dialógica. Perspectivas para la enseñanza de la filosofía griega, Argentina, Libros del Zorzal.

Mitscherling, J., 1985: «Plato's Agathon»s Sophocles: Love and Necessity in the Symposium», Phoenix 39, 4, pp. 375-377.

Nightingale, A., 1992: «Plato’s Gorgias and Euripides' Antiope», Classical Antiquity 11, pp. 121-41.

Nightingale, A., 1995: Genres in Dialogue: Plato and the Construct of Philosophy, CUP.

Nussbaum, M., 1986: The Fragility of Goodness: Luck and Ethics in Greek Tragedy and Philosophy, CUP.

O’Brien, D. 2002: «Die Aristophanes' Rede in Symposion: der empedokleische Hintergrund und seine philosophische Bedeutung», en Janka, M. y Schäfer, Ch. (eds.), Platon als Mthologe, Stuttgart, pp. 176-193. 
Padel, R., 1997: A quien un Dios quiere destruir, antes lo enloquece. Elementos de la locura griega y trágica, Buenos Aires, Ediciones Manantial.

Platón, 1968: Diálogos III. Fedón, Banquete, Fedro, trad., introducción y notas por C. García Gual, M. Martinez Hernández, E. LLedó Iñigo, Madrid, Gredos.

Platón, 1986: Diálogos IV. República, trad., introducción y notas por C. Eggers Lan, Madrid, Gredos.

Racket, A, 2005: «El eros anti-trágico del Banquete de Platón», en Mársico C., Castello L. A. (eds.), El lenguaje como problema entre los griegos, Buenos Aires, Altamira., pp. 101-108.

Robin, L., 1908: La Théorie Platonicienne de l'Amour, Paris, Félix Alcan.

Robin, L. (ed.), 1938: Platon. Ouvres Completes. Tome IV - $2^{\circ}$ Partie. Le Banquet, Paris, Les Belles Lettres.

Rodríguez Adrados, F., 1969: «El Banquete platónico y la teoría del teatro», Emerita. Revista de Lingüistica y Filología Clásica 37, pp. 1- 28.

Rodríguez Adrados, F., 1992: «La lengua de Sócrates», Méthexis 5, pp. 29-52.

Rowe, C. (ed.), 1998: Plato: Symposium, Warminster, Aris and Phillips.

Sheffield, F., 2001: «Alcibiades' Speech: A Satyric Drama», Greece \& Rome, Second Series 48, 2, pp. 193-209.

Sider, D., 1980: «Plato's Symposium as Dionysian Festival», Quaderni Urbinati di Cultura Classica, New Series 4, pp. 41-56.

Soares, L., 1999: «La concepción del poeta tragicómico en el Banquete de Platón», en Buzón, R., Cavallero, P., Romano, A., Steinberg, Ma. E. (eds.), 2002: Los estudios clásicos ante el cambio de milenio. Vida, muerte y cultura, T. 2, Facultad de Filosofía y Letras, Universidad de Buenos Aires, pp. 477-486.

Soares, L., 2009: «Estudio preliminar», en Platón (trad. C. Mársico), Banquete, Buenos Aires, Miluno.

Suárez de la Torre, E., 2002: «En torno al Banquete de Platon», en Eros na literatura e filosofia antiga: homenagem a Victor Jabouille, Coimbra, pp. 63-100.

Trivigno, F., 2009: «Paratragedy in Plato's Gorgias», en Inwood, B. (ed.), Oxford Studies in Ancient Philosophy Volume XXXVI, OUP, pp. 73-105.

Usher, M., 2002: «Satyr Play in Plato's Symposium», The American Journal of Philology vol. 123, 2, pp. 205-228.

Wieland, W., 1999: «La crítica de Platón a la escritura y los límites de la comunicabilidad», trad. Alejandro Vigo, Méthexis 4, pp.19-37.

Fecha de recepción de la primera versión del artículo: 06/11/2011

Fecha de aceptación: 12/12/2012

Fecha de recepción de la versión definitiva: 22/12/2012 